\title{
EL SOCIALISMO MALAgUEÑo: PARTIDO Y SINDICATO A FINALES DEL SIGLO XIX.
}

\author{
María Dolores GRANADOS SANCHEZ \\ Manuel MORALES MUÑOZ \\ Universidad de Málaga
}

\section{$\underline{\text { RESUMEN }}$}

Estudio de los primeros años del socialismo malagueño en su vertiente política y sindical.

Palabras clave: España, siglo XIX. Socialismo. Málaga.

\section{$\underline{\text { SUMMARY }}$}

Analysis of the first years of the socialist movement in the city of Malaga, in a double point of view, political and sindical.

Keywords: Spain, XIXth century. Socialism. Malaga.

\section{INTRODUCCIÓN}

Como para otros ámbitos de la España de entresiglos, en el mundo obrero se superponen lo tradicional y lo nuevo: el pequeño taller artesanal y la gran fábrica; el trabajador de oficio y el proletario; las tradicionales formas asociativas y el nuevo sindicalismo; las seculares manifestaciones de protesta y la huelga general (Morales, 1996).

Durante aquellos años se relanzó la construcción ferroviaria; la industria fabril conoció un gran avance, en particular en Cataluña, y nació la gran siderurgia, asentada en Vizcaya; pero fuera de estos sectores y de otros como el eléctrico, los tranvías, el gas o el minero, donde se dio la mayor concentración de capitales y hombres, una gran parte de las empresas industriales continuaban siendo de pequeño tamaño, con una media de 10-13 trabajadores por establecimiento. Si en 1887 los obreros fabriles eran unos: 243.000 , los pertenecientes a "artes y oficios" alcanzaban los 823.340; cifras similares a las existentes para 1900, cuando el porcentaje de las "artes y oficios" se situaba en torno al 65 por ciento del total industrial ${ }^{1}$. Tampoco habían cambiado en demasía las condiciones de vida de las clases obreras. Aunque a finales de siglo la jormada habitual era de 11 horas, esta reducción quedaba compensada por una intensificación en el ritmo de trabajo, lo que hacía más dura y penosa la tarea. Los salarios continuaron estancados y las condiciones de higiene y seguridad en el 
trabajo eran pésimas. A esto se le añadía el paro crónico, el analfabetismo y el desastroso estado de las viviendas (Ralle, 1989, y Soto Carmona, 1989).

No escapará a esta situación la provincia de Málaga. Si en la capital y en las cabeceras de comarca (Antequera, Ronda, Vélez Málaga, Marbella) la renovación del tejido industrial (Parejo Barranco, 1990) y el desarrollo urbano (Rubio, 1996) se vieron acompañados por la emergencia y concreción de nuevos sectores y nuevas estrategias obreras (Morales, 1995), no es menos cierto que la estructura productiva seguia asentándose fundamentalmente en el sector agrario y, dentro del sector industrial, en el artesanado. Por ello no tendrá nada de extraño que las filas del socialismo malagueño sigan nutriéndose de trabajadores empleados en las llamadas "artes y oficios"; lo que no impidió que muchos otros de sus afiliados se reclutasen entre los trabajadores del textil o del ferrocarril (Castillo, 1983). Una población obrera, la malagueña, que en su conjunto adolecia de los mismos problemas ya enunciados a nivel nacional, tal como tuvo ocasión de señalar en 1884 el cónsul de los Estados Unidos en Málaga, Mr. Marston'.

Estudiar el proceso de formación y la evolución del socialismo malagueño, en su doble vertiente política y sindical, durante los últimos años del siglo XIX es lo que pretendemos con este trabajo. Con tal objetivo trataremos de dilucidar las vicisitudes por las que atravesó la organización. Nos referiremos igualmente a aquellos conflictos que marcaron tal proceso; como trataremos de "medir" el eco que encontró en Málaga guiándonos por la difusión de El Socialista y por los resultados obtenidos en las distintas convocatorias electorales realizadas en esos años. Y todo ello manteniendo como referente obligado la evolución seguida por dicho movimiento político-sindical a nivel nacional.

\section{ORGANIZACIÓN Y PRIMEROS PASOS.}

Pasada la conmoción represiva de la Restauración, comenzo a dar señales de vida el núcleo de la Nueva Federación Madrileña de la Internacional. La mayor parte de sus miembros habían continuado vinculados dentro de la Asociación del Arte de Imprimir, creada en 1873 y presidida por Pablo Iglesias desde el 10 de mayo de 1874 hasta enero de 1885 (Morato, 1925). De alli salieron socialistas destacados como Antonio Garcia Quejido y Matias Gómez Latorre. Paralelamente, el malagueño José Mesa, que residía en Paris, mantuvo contactos con Marx, Engels y Lafargue, y trabó gran amistad con Jules Guesde; cuya influencia en el socialismo español fue de gran importancia (Guereña, 1979).

El siguiente paso en este proceso se dió el 2 de mayo de 1879, con el nacimiento del Partido Democrático Socialista Obrero Español en una fonda de la calle Tetuán de Madrid. De sus 25 fundadores 20 eran obreros 
(16 tipógrafos, 2 joyeros, 1 marmolista y 1 zapatero). La reunión acordó constituir una comisión, integrada por Pablo Iglesias, Alejandro Ocina, Gonzalo Zubiaurre, Victoriano Calderón y Jaime Vera, para redactar un proyecto de programa. La primera asamblea del Partido Socialista se celebró el 20 de julio del mismo año, nombrándose en ella la primera Comisión Ejecutiva, que estaba constituida por Pablo Iglesias en la Secretaria; Tesorero era Inocente Calleja; Contador, Alejandro Ocina; Vocales, Victoriano Calderón y Gonzalo Zubiaurre.' El programa inicial aprobado decia: "El Partido Socialista Obrero Español declara que su aspiración es: la abolición de clases, o sea, emancipación completa de los trabajadores, transformación de la propiedad individual en propiedad social o de la sociedad entera, posesión del poder politico por la clase trabajadora" (Morato, 1918: 81-89). Durante 1879 se crearon igualmente las agrupaciones de Barcelona y Guadalajara, y a comienzos de la década siguiente se inicia el proceso de implantación de la organización socialista en la provincia de Málaga, constituyendo, junto a Linares, el núcleo de implantación social-ugetista más temprano y constante de Andalucia (Calero, 1979: 38).

Pero los antecedentes del socialismo malagueño hay que buscarlos también en los años del sexenio democrático, cuando, coincidiendo con la ruptura entre bakuninistas y "autoritarios" en el seno de la Federación Regional Española (FRE) de la AIT, el tonelero Rafael Salinas Sánchez (1850-1919) defienda a titulo casi individual los postulados del semanario La Emancipación y de la Nueva Federación Madrileña (Morales, 1988). Unos vinculos que se mantendrán en los años siguientes, a pesar de la represión que se cernió sobre el movimiento obrero malagueño y de la continua movilidad geográfica de Salinas, obligado por la presión patronal y las dificultades económicas que atravesaba su oficio. Establecido en Valdepeñas entre 1878 y 1881 , alli se reafirmará en sus planteamientos doctrinales, reanudando sus contactos con Pablo Iglesias y la ya constituida Agrupación Socialista Madrileña, que le sirvieron de base para reorganizar a los toneleros malagueños e impulsar el proceso de formación de la corriente socialista en la provincia ${ }^{3}$ (Morales, 1989: 111-121).

Ya en agosto de 1880 siete obreros antequeranos fueron detenidos por difundir "propaganda socialista-revolucionaria"4 . Apenas dos años después, exactamente el 13 de marzo de 1882, se fundaba la Sociedad de Toneleros, según consta en la relación de sociedades elaboradas por el Gobierno Civil de la provincia ${ }^{5}$. Y en el verano del mismo 1882 , el órgano del partido obrero francés daba cuenta de que se estaba organizando, entre otras, la sociedad de tipógrafos de Málaga ${ }^{6}$; a la que se unirían a lo largo de 1883 las de carpinteros, zapateros y albañiles (Aisa y Arbeloa, 1975: 218), evidenciando el peso especifico que las llamadas "artes y oficios" seguían teniendo en el conjunto del sector industrial. Unas circunstancias, éstas, que no fueron obstáculo para que el socialismo arraigase con igual fuerza entre los trabajadores de la industria textil (Castillo, 1983), tal y como 
venía ocurriendo por el mismo tiempo en Cataluña (Gabriel, 1990: 49). Para Castillo, la razón de esa incidencia no era otra que la precariedad laboral y salarial en que se encontraban los obreros y obreras de Industria Malagueña S.A. ante la dura competencia del textil catalán, lo que motivaria numerosos conflictos en las décadas finales del siglo. Partiendo de esta base, en 1884 Rafael Salinas y Antonio Valenzuela fundaban un llamado Ateneo Obrero, germen de la Agrupación Socialista (Morato, 1928), que, constituida definitivamente al año siguiente, se convertía en la quinta en el proceso de implantación nacional, después de Madrid (1879), Barcelona (1879), Guadalajara (1880) y Manresa (1880) (Castillo, 1995:2).

En 1886 Iglesias hacia una gira de propaganda por Andalucía y el día 12 de marzo de ese mismo año salía a la luz el primer número del semanario El Socialista, órgano de prensa del nuevo partido que estaría muy influido por el periódico del mismo nombre (Le Socialisme) publicado por la corriente "guesdista" (Castillo, 1976a). Resultado de ello, el espiritu societario caló entre los obreros malagueños. Ese mismo año la Agrupación Socialista recogía más de 400 firmas en apoyo de la campaña iniciada por el Arte de Imprimir para el cumplimiento de la Ley Benot sobre el trabajo infantil (Morato, 1925). A principios de 1887, los toneleros, que contaban con 654 afiliados y que atravesaban una crítica situación en todo el país, protagonizaron una sonada huelga que concluyó en abril del mismo año en fracaso (Castillo, 1983: 122-124). El 22 de agosto de ese mismo año los tipógrafos procedían a su reconstitución al fundar El Arte de Imprimir ${ }^{7}$, que seria la única sociedad de resistencia malagueña que estuvo representada en el Congreso constituyente de la UGT en 1888; aunque, como apunta el mismo Castillo (1983:125), adoleció de una marcada debilidad orgánica que le llevó a su disolución temporal en 1889. Otro oficio que se constituyó en sociedad este mismo año de 1887 fue el de los litógrafos, que lo hacían el 7 de diciembre con la Asociación litográfica ${ }^{8}$.

Del 23 al 25 de agosto de 1888, el Partido Socialista celebraba su primer Congreso nacional, que, presidido por Pablo Iglesias, contó con la asistencia de 18 delegados de 20 agrupaciones. Alli se estableció el Programa cuyos puntos básicos eran: "1 ${ }^{\circ}$. La posesión del poder politico por la clase trabajadora. $2^{\circ}$. La transformación de la propiedad individual y corporativa de los instrumentos de trabajo en propiedad común de la sociedad entera. $3^{\circ}$. La organización de la sociedad sobre la base de la federación económica, el usufructo de los instrumentos de trabajo por las colectividades obreras, garantizando a todos sus miembros el producto total de su trabajo; la enseñanza integral a los individuos de ambos sexos en todos los grados de la ciencia, de la industria y de las artes" (Morato, 1918: 114-117).

Al año siguiente acudieron Iglesias y Mesa al Congreso de la II Internacional; y en 1890 el triunfo electoral de los socialistas alemanes tuvo gran repercusión en España. Fue el año del segundo Congreso del 
P.S.O.E. en Bilbao, en el que los socialistas españoles, acatando el acuerdo de la II Internacional, celebraron el $1^{\circ}$ de Mayo. En Madrid, una manifestación calculada en $\mathbf{2 5 . 0 0 0}$ personas fue desde el Prado, por la calle de Alcalá, hasta la Presidencia del Consejo, donde Sagasta recibió a la comisión. También la hubo en Barcelona, donde los socialistas lograron reunir alrededor de sus propuestas a numerosas sociedades obreras no integradas orgánicamente en la UGT (Gabriel 1990: 49). Como la hubo en Málaga. Teniendo como telón de fondo el mitin organizado a finales de abril con la participación del mismo Pablo Iglesias, la manifestación tuvo lugar el domingo 4 de mayo, originando : su aplazamiento una agria polémica entre socialistas y anarquistas a propósito del día de celebración y del contenido que se le debía conferir al acto (Nadal, 1986).

Sin embargo, el año 1890 quedaría en los anales del socialismo malagueño por otros motivos. A los diversos conflictos protagonizados por los trabajadores durante este año, entre otros por los portuarios ${ }^{9}$, los fundidores ${ }^{10}$ y las tejedoras de Industria Malaguena S.A., en cuya huelga esta corriente desempeñó un papel central; había que sumar las consecuencias del proceso político abierto con el reconocimiento del sufragio universal y, sobre todo, la consolidación del proceso organizativo en el que estaban inmersos. Ya en el verano de 1889 el periódico local $L a$ Unión Mercantil se había hecho eco de un manifiesto de los socialistas malagueños en el que mostraban su deseo de "perfeccionar y ampliar su organización todo lo posible"11. Y al año siguiente, en la costa oriental, el mismo día en que los socialistas de la capital celebraban el primer $1^{\circ}$ de mayo, se creaba una sección de agricultores en Cala de Benagalbón, que junto a la de Oficios varios contarán en noviembre de ese mismo año con 100 afiliados (Castillo, 1983: 141), medio centenar de los cuales impulsarán la creación de la Agrupación Socialista de la localidad en marzo de 1891; y que venía a sumarse a la ya existente en Vélez-Málaga, constituida en junio de 1890 , y sin duda alguna el núcleo más importante de la provincia junto al de la capital.

Poco a poco, el socialismo malagueño se iba consolidando. A ello contribuyó la exitosa labor propagandística y societaria promovida por obreros como Rafael Salinas, Antonio Valenzuela, Antonio Campos, trabajador de la fábrica textil Industria Malagueña S.A., Pedro Puertas, vocal de la Junta Local de Reformas Sociales en 1905, etc. (Morales, 1989). Aunque tampoco cabe olvidar lo que S. Castillo (1995: 4) ha calificado como la "euforia despertada entre los trabajadores en torno a las celebraciones del $1^{\circ}$ de mayo y la participación electoral de 1891", y que para él serían factores claves en el auge experimentado por el Partido Socialista a nivel nacional.

Desde entonces, la intensa actividad propagandística de éste núcleo y su importante labor organizativa se vieron reforzadas con los frecuentes viajes del mismo Pablo Iglesias y por la difusión de El Socialista; 
importante fuente documental para el estudio del socialismo malagueño, debido a su regularidad y estabilidad de edición. Además de su función como vehículo ideológico y como nexo de unión del partido, los datos aportados por la "Correspondencia administrativa" nos permiten conocer la difusión del periódico y de algunos folletos socialistas en Málaga, constituyéndose de esta manera en un buen indicador para seguir grosso modo la evolución de los efectivos socialistas en la provincia. Por el estudio realizado por S. Castillo (1982) sabemos como entre 1886 y 1889 se distribuían semanalmente en Málaga entre 30 y 45 ejemplares; cifras que se elevaron considerablemente a lo largo del año 1890 , en que se alcanzaron los dos centenares, y 1891, al llegarse a los más de 500 en el mes de mayo y que constituiría el punto álgido en su difusión durante el periodo estudiado. Paralelamente, los socialistas malagueños recibían, entre finales de octubre de 1886 y 1890, más de un centenar (104 ej.) de ejemplares del Manifiesto Comunista de Marx y Engels; 84 del folleto de Engels, Socialismo utópico y socialismo científico; y 13 ejemplares de una edición resumida de $E l$ Capital, debida a G. Deville, y que se puso a la venta en diciembre de 1887 (Castillo, 1982: 182-184). Aun cuando no se pueda establecer una relación directa entre ejemplares distribuidos y número de afiliados, de lo que no cabe duda es que el crecimiento observado viene a coincidir con una mayor actividad del socialismo malagueño, inmerso en estos primeros anos noventa en un proceso de organización sindical y lucha contra el capital.

\section{LA BATALLA ELECTORAL.}

Habiendo entrado en vigor en 1890 la ley del sufragio universal, Cánovas convocó elecciones legislativas para el $1^{\circ}$ de febrero de 1891. Al pasar el número de electores de unos 850.000 a poco menos de cinco millones, los partidos se vieron obligados a realizar un replanteamiento de las campañas electorales, que se centrarían desde ese momento en los mítines y en las concentraciones de masas. El P.S.O.E presentaba su candidatura en cinco circunscripciones y trece distritos, entre otras Málaga y Vélez-Málaga, donde desde enero de ese año las respectivas agrupaciones se dedicaron a preparar la campaña electoral. Igualmente se designaron los candidatos a Cortes, correspondiendo los nombramientos a Pablo Iglesias y Rafael Salinas, para la circunscripción de Málaga, y a este último para el distrito uninominal de Vélez-Málaga ${ }^{12}$. Siguiendo las líneas programáticas del P.S.O.E a nivel nacional, uno de los objetivos inmediatos en la estrategia política defendida en Málaga era fomentar la participación obrera en las elecciones con el fin de fortalecer la organización y acabar con el caciquismo (Macarro, 1988: 107). Para ello, la actuación del comité electoral que había sido elegido para dirigir la campaña se centró en la publicación de un manifiesto en el que aparecen los puntos claves del pensamiento socialista del momento y que son los siguientes: $1^{\circ}$. Participación electoral, aunque no se hiciera en las anteriores elecciones 
municipales y provinciales. $2^{\circ}$. Dar la batalla a los partidos burgueses, englobando en este término tanto a los dinásticos como a los republicanos. $3^{\circ}$. Conseguir el mejoramiento y redención del proletario por el esfuerzo de su propia clase. $4^{\circ}$. Rechazo de todo tipo de coaliciones con las fracciones políticas burguesas ${ }^{13}$.

Aun cuando los datos sobre los resultados obtenidos por el partido socialista varían según la fuente de información, sea su órgano de prensa $a^{14}$, que estima el número de votos totales conseguidos en el país en algo más de 5.000, o los escrutinios oficiales que lo fijan en 3.872 , lo que si nos muestran las cifras es la importancia del socialismo malagueño, sólo superado por las tradicionales áreas de implantación del partido. Asi, frente a los 330 votos recibidos en la circunscripción de Málaga, en Madrid se consiguieron 1.398; 437 en Bilbao; 406 en Vich, y 393 en Mataró: Lejos quedaban los 257 votos de Alicante; los 217 de Valmaseda; los 121 de Valencia; los 43 de Játiva o los 33 de Vélez-Málaga (Castillo, 1983: 144145).

Para las elecciones de 1893, de nuevo los lugares elegidos para presentar la candidatura socialista son los de mayor implantación del partido. Sin embargo, a diferencia de los comicios de 1890, en estas elecciones Andalucía superó a Madrid, el País Vasco o Valencia por el número de votos obtenidos. El alto porcentaje se debió a la importancia del movimiento socialista malagueño, que aquel año alcanzó su mejor situación relativa en el conjunto español. Según la estimaciones de $E l$ Socialista ${ }^{15}$, que no coinciden con las cifras que da Crespillo (1990: 137): 533 votos para Salinas y 501 para Iglesias, Málaga habría obtenido un total de 643 votos, seguida de Linares con 275, por 709 en Madrid, 315 en Alicante, 304 en Valencia, 307 en Palma, etc.

En los' años siguientes, coincidiendo con la crisis sufrida por la organización socialista en toda Andalucía, el porcentaje de votos es mínimo. Para Calero (1979: 48-49), los resultados conseguidos, con ser mediocres, se lograron salvar gracias a las aportaciones de Jaén y Málaga. Sin embargo, por las cifras oficiales que recoge el Boletín Oficial de la Provincia de Málaga en las distintas convocatorias, deducimos que tal incidencia de la provincia fue menor. En $1896^{16}$ los candidatos socialistas obtuvieron en Málaga capital setenta y un votos (69 Iglesias y 2 Salinas), y 22 en la circunscripción de Vélez Málaga (Salinas), frente a los 998 votos que el partido recibió en la región. Más favorables fueron los resultados de los comicios de $1898^{17}$, en los que consiguieron 113 votos en la circunscripción de Málaga, repartidos entre Pablo Iglesias (60) y Salinas (53), y 4 (Iglesias) en el distrito de Vélez; y que a nuestro juicio se deberia a las campañas y movilizaciones emprendidas por los socialistas contra la guerra de Cuba (Serrano, 1979). Como favorables fueron los de 1901, una vez pasada "la travesia del desierto" que llevó a los socialistas malagueños a cobrar nuevo auge. Este año, en la capital las cifras se elevaron a 224 
votos para Iglesias y 179 para Salinas, mientras que en Vélez Málaga la gran novedad radica en los 133 votos que consiguió José Verdes Montenegro ${ }^{18}$.

\section{ORGANIZACIÓN SINDICAL Y LUCHA CONTRA EL CAPITAL.}

Aun cuando las relaciones entre partido y sindicato fueron bastante ambiguas durante las primeras décadas de vida de ambas formaciones, sin una clara separación entre las actividades de uno y otro (Pérez Ledesma, 1979), por los datos con que contamos parece claro que el mayor dinamismo observado entre 108 socialistas malagueños a comienzos de los años 1890 se debió, junto a otros factores ya citados, a la pujanza del movimiento sindical. A nivel nacional, el punto de partida del sindicalismo ugetista se sitúa en 1887, cuando el centro obrero de Mataró se dirigió al Centro Obrero de Barcelona pidiéndole la convocatoria de un Congreso obrero que coincidiese con la Exposición Universal que debía celebrarse en la ciudad condal en el verano de 1888. Celebrado el Congreso en la casa número 29 de la calle de Talleres, del 12 al 14 de agosto de 1888, con asistencia de 25 delegados que representaban a 41 secciones (26 de Cataluña), en él nació la Unión General de Trabajadores (U.G.T.) cuyo primer Comité Nacional estuvo presidido por Antonio García Quejido. A fines de año la U.G.T. contaba con 27 secciones y 3.555 afiliados (Tuñón de Lara, 1977).

Apenas habían transcurrido unos meses de este acontecimiento, cuando en septiembre de 1890 las 12 secciones que formaban la Federación de Sociedades Obreras de Málaga decidían integrarse en la U.G.T. ${ }^{19}$. La iniciativa había partido del comité de la agrupación socialista de la capital, que solicitó la documentación necesaria en mayo de $1890^{20}$. Las doce secciones contaban con 1.254 asociados en noviembre de 1890 , reclutados, sobre todo, entre los trabajadores de la industria siderometalúrgica y textil y entre los toneleros y trabajadores del muelle. A ellos había que añadir los de la secciones de Agricultores y de Oficios varios de Cala de Benagalbón que contaban con otros 100 , y que, en conjunto, representaban una cuarta parte del total de los efectivos con que contaba la Unión a nivel nacional. Prueba del éxito que el social-ugetismo estaba alcanzando en Málaga es la carta dirigida por la Federación de Sociedades Obreras de la provincia al Comité de la U.G.T., en la que se vanagloriaba de "contar con una organización bien sólida y disciplinada"22.

Paralelamente, este movimiento organizativo se vio acompañado por una notable labor de propaganda. Al tiempo que seguian difundiéndose los textos de Marx y Engels recibidos a través de la redacción de El Socialista, en octubre de 1890 la Agrupación de Málaga creó una Biblioteca Socialista destinada a dar a conocer folletos doctrinales escritos por militantes locales, en los que se condenaba a la burguesía a la par que se 
presentaban las ventajas y beneficios reportados por la asociacion en las filas del socialismo. Todo ello de una manera bastante simple y maniquea. Es este el caso del folleto titulado Los explotadores y sus victimas (1890), con cuya venta se pensaba socorrer económicamente a su autor, Francisco Rico, despedido de Industria Malagueña durante el conflicto de ese año ${ }^{21}$; como sería el caso del ya citado folleto publicado por Rafael Salinas en 1903 con el título de Obligado por la burguesía. Refutación de sofismas burgueses. En julio de 1890, coincidiendo con la inauguración de un nuevo local en calle Cerrojo, 36, la Federación aprobaba el establecimiento de una escuela y un gabinete de lectura, así como la organización de conferencias dominicales: la primera de las cuales ("Conveniencia de la asociación") tuvo lugar el día 26, contando con la participación de Rafael Salinas, Antonio Campos y Francisco León ${ }^{22}$.

Sin embargo, no hubo de pasar mucho tiempo para que el desarrollo del movimiento asociativo y el empuje reivindicativo registrado durante el bienio 1890-1892 conociese ciertos altibajos que hacían presagiar el estancamiento iniciado a partir de 1894. Un declive en la actividad socialugetista local que vendría a confirmar la hipótesis de Santiago Castillo (1986), para quien la implantación del socialismo se llevaba a cabo lenta y precariamente en el marco nacional; y es que, por encima de coyunturas favorables, la organización socialista adolecfa en esta primera etapa de una manifiesta debilidad orgánica.

En febrero de 1892 el numero de secciones malagueñas adscritas a la U.G.T. había bajado a nueve, lo que llevó al comité de la Federación malagueña a dirigir una comunicación al Comité nacional participándoles que "en virtud de la apatía que en todas las secciones se observa", creían necesario organizar una campaña "para hacer propaganda y levantar el espiritu societario" 23 . La ocasión la deparó la celebración del II Congreso de la Unión, que se celebró en la capital malagueña en octubre de 1892, y que no fue suficiente para evitar que continuase la pendiente iniciada, quedando a esa fecha tan sólo seis secciones con 356 afiliados. Un número que se incrementaría notablemente en 1894, al encontrarse adheridas a la Unión, además de La Fabril, sociedad compuesta por casi un millar de trabajadores de Industria Malagueña S.A., las secciones de agricultores, hortelanos, toneleros, carreros, carpinteros y oficios varios; y que evidenciaba el peso específico que el socialismo malagueño mantenía en Andalucia, donde sólo se hallaban afiliados los trabajadores en hierro de Linares y una sección de tipógrafos de Jaén (López Estudillo, 1994: 797).

A la par del desarrollo del sistema organizativo se fueron divulgando y caracterizando los principios básicos de la estrategia sindical ugetista, que partía de un nuevo planteamiento teórico basado en la creencia de una revolución social como la culminación de un largo proceso de reformas cada vez más profundas de la situación obrera. De este modo las preocupaciones dominantes en la propaganda socialista pasaban por el 
fortalecimiento de la organización y de la unión de la clase.obrera, la combinación de la lucha económica y la actividad política y el abandono de toda aventura revolucionaria. Este planteamiento táctico general fue sostenido siempre por Pablo Iglesias, principal propagandista socialista de aquella etapa. La huelga, que era el arma fundamental en la lucha obrera, necesitaba de unas condiciones previas imprescindibles para el triunfo de las reivindicaciones. Como ha señalado Pérez Ledesma (1979), éstas eran la existencia de una sólida organización a nivel local y nacional; el pago de cuotas suficientes para disponer de cajas de resistencia con los fondos necesarios para sostener el conflicto, y la prudencia en las reivindicaciones. Era, pues, una estrategía sindical moderada en la que la prudencia y las negociaciones como solución a los conflictos contaban con un papel de primer orden, en oposición a la táctica defendida por las posiciones anarquistas o anarcosindicalistas que eran favorables al apoliticismo, a la acción directa y a la huelga general, como evidencia la polémica surgida a propósito de la celebración del $1^{\circ}$ de Mayo.

Pero esta estrategia no fue suficiente para frenar las ansias reivindicativas de los trabajadores malagueños, que durante estos primeros años de la década protagonizaron conflictos de gran dureza. El año 1890 fue testigo del primero de los conflictos protagonizados por las más de 2.000 obreras de la fábrica textil Industria Malagueña S.A., que concluyó con el fracaso y la detención de algunos de los dirigentes (Nadal, 1986). En septiembre los trabajadores del muelle vieron aceptadas sus reivindicaciones después de tres días de huelga ${ }^{24}$, y a principios de octubre iniciaban un paro los trabajadores de la sociedad de fundidores ${ }^{25}$.

Paralelamente, tal como ya hemos comentado, en el seno de Industria Malagueña S.A. se había fundado La Fabril, sociedad que llegó a agrupar a un millar de trabajadores, constituyendo el mayor slndicato textil de fabrica de la época. Segun ha subrayado S. Castillo (1986: 18), La Fabril habría participado sin éxito en el proyecto de crear unas Tres Clases de Vapor de ámbito nacional, lo que llevó a los socialistas en 1894 a crear la Unión Fabril y Algodonera, formada mayoritariamente por los obreros textiles malagueños y que contó con una vida efímera. Teniendo como telón de fondo estas iniciativas, en julio de 1892 los trabajadores de la industria textil malagueña se declaraban en huelga por el despido de un obrero que había impulsado dos meses antes una petición a la patronal; concluyendo satisfactoriamente el conflicto a finales de julio con la readmisión del obrero despedido ${ }^{26}$.

Después de nuevos conflictos acaecidos en 1893, en 1894 tiene lugar una de las huelgas más importantes del período y la más destacada de las que tuvieron como escenario la fábrica textil, tanto por la resonancia y el grado de movilización alcanzada como por las graves consecuencias que acarrearía a la organización socialista de la provincia. El desencadenante fue la sanción establecida por la Junta Pericial de la Fabril encargada de los 
trabajadores, que suspendió con un día de trabajo y sueldo a un obrero que había faltado a un encargado. El 27 de septiembre la empresa declaraba el lock-out y despedía a varios obreros, además de exigir la disolución del sindicato socialista y la suspensión de la Junta Pericial. Los socialistas desplegaron una importante campaña de solidaridad en la que participaron personalmente Rafael Salinas, delegado del comité de huelga, y el mismo Pablo Iglesias, al que le costó dos procesos y cuatro meses de cárcel. Después de tres meses de resistencia, la huelga se saldó con una rotunda derrota para los obreros, quienes volvieron al trabajo sin ver satisfecha ninguna de sus reivindicaciones (Calero, 1979; Nadal, 1986).

\section{ESTANCAMIENTO Y CRISIS ORGÁNICA.}

A pesar del declive observado ya desde 1892, fue en 1894 , presumiblemente como consecuencia del fracaso sufrido en la huelga de este año, cuando èl socialismo malagueño entró en una fase de atonía de la que no saldría hasta comienzos del nuevo siglo. La represión policiaca y patronal motivó la huida de Salinas y obstaculizó la actividad de los socialistas, abriéndose así un periodo en el que se intensificaron las dificultades para la organización en su doble vertiente política y sindical.

El mismo año 1894 se prohibían sendas manifestaciones políticas en Benamocarra y Vélez-Málaga; al tiempo que desaparecía la agrupación de Benagalbón, que se había constituido el 24 de marzo del mismo año con medio centenar de afiliados. Al año siguiente quedaba desorganizada la agrupación de Cala de Benagalbón, que había estado representada en el IV Congreso (1894) por el delegado malagueño Antonio Campos, manifestando ya por entonces una notable pérdida de entidad. Ese mismo año los intentos de los socialistas de Chilches, respaldados por destacados militantes de la capital como Salinas, Rueda, Puertas y Salvador González se veían obstaculizados por el juez de Vélez Málaga, quien los persuadió de la conveniencia de retirar el reglamento; y aunque el 24 de junio de 1895 la Agrupación de Chilches iniciaba su singladura, ésta apenas se mantuvo hasta agosto de 1896, cuando dejó de existir. De este modo el partido socialista veia desaparecer tres de sus agrupaciones, dos de las cuales -Benagalbón y Chilches- sólo habían disfrutado de una existencia fugaz, quedando su implantación circunscrita a la capital y a Vélez-Málaga hạsta 1900 (Castillo, 1995).

Pero el fracaso de los obreros textiles en la huelga de 1894 no solo arrastró al socialismo malaqueño a un franco declive, sino que además generó el hundimiento de la implantacion ugetista en toda Andalucía, ya que de los 1.800 federados andaluces(12 secciones)con que contaba la Unión en 1893, La Fabril agrupaba a la mayoría de ellos: 956. Así, en junio de 1896 sólo quedaban adheridas a la central sindical dos pequeñas secciones andaluzas: los tipógrafos y los agricultores de Málaga. Dadas de 
bajas éstas después de 1896, el sindicalismo socialista en Andalucía fue un autentico páramo hasta 1900, fecha en la que ingresaron 108 Alpargateros de Vélez-Málaga; a los que se unirían en 1901 dos secciones más. Con ello y todo, el panorama no podía ser más desalentador, máxime cuando este último año la Unión contaba con 172 secciones y 29.383 afiliados en todo el país (López Estudillo, 1994: 798-799).

Sin embargo, esta situación de crisis orgánica no fue nada exclusiva de Málaga, sino que afectó al socialismo español en su conjunto. Salvo en Madrid y Barcelona, las restantes agrupaciones socialistas manifestaban análoga inestabilidad y precariedad orgánica a la ya apuntada para el caso de Málaga, según sugiere S. Castillo (1989), a la falta de imbricación entre las bases sociales en que pretendían implantarse. Como consecuencia de esta situación, a partir de 1894 , el mismo año en que la organización socialista malagueña entrará en crisis, el P.S.O.E. emprendía un amplio proceso de apertura de su estructura organizativa para paliar los continuos enfrentamientos con otros sectores politicos y posibilitar la entrada en el partido de nuevos colectivos que ensancharan la base sobre la que se apoyaba. Para Pérez Ledesma las preocupaciones dominantes en la propaganda socialista durante estos años pasaba por "el fortalecimiento de la organización y de la unión de la clase obrera, la combinación de la lucha económica y la actividad política y el abandono de toda aventura revolucionaria" (Pérez Ledesma, 1979: 137).

En este contexto, marcado por la desarticulación orgánica del socialugetismo y por el deseo de ensanchar la base social, surgían en la provincia de Málaga dos iniciativas que a nuestro juicio cumplían el mismo fin: mantener vivo el "ideal" socialista bajo nuevas formas de sociabilidad en las que se conjugaban la actividad política y sindical con la funcionalidad instructiva y recreativa. Se trata del Círculo Socialista de Obreros y de La Unión Social. Sociedad Instructiva y Recreativa. Dos iniciativas que vendrían a paliar, de alguna manera, las dificultades conocidas por el socialismo malagueño durante la segunda mitad de la década de los noventa.

Creado el primero de ellos en Vélez-Málaga en febrero de 1893, el Círculo conocerá serias dificultades económicas durante sus primeros meses de existencia, tal como se desprende del escrito remitido el 3 de mayo de 1894 por el Secretario del centro, Manuel Muñoz, al Gobernador civil, notificándole su disolución ante la imposibilidad de sostenerlo materialmente. Unas circunstancias que se verían superadas, sin embargo, con prontitud, pues el 6 de julio del mismo año se dirigía nueva comunicación a la autoridad provincial, dándole cuenta de la reanudación de las actividades ${ }^{27}$. Más tardía fue la legalización de La Unión Social, que tuvo lugar en mayo de 1896, una vez aprobados sus estatutos por los socios fundadores el dia 8 de marzo ${ }^{28}$. Aun cuando formalmente el objeto de esta sociedad era "instruir y educar a cuantos individuos aspiren a su 
emancipación económica" (art. $1^{\circ}$ ) y ayudarlo en casos de desgracias laborales o personales (art. 12), de la misma manera en sus estatutos se hace profesión de fe socialista, al aceptar "en todas sus bases el programa y organización general del Partido Obrero", cuyas doctrinas contribuiría a difundir entre los trabajadores (Art. $2^{\circ}$ ). Las razones de esta "tibieza" programática habría que verla tanto en la represión subsiguiente a la huelga de 1894 como en la nueva estrategia seguida por el PSOE a nivel nacional desde mediados de la década de los noventa, con lo que la sociedad se convertía, de hecho, en la "cobertura" del socialismo en Málaga en el difícil periodo que atravesó después de 1894, tal como ha apreciado Cristóbal García Montoro (1985).

\section{UNA TIMIDA REORGANIZACIÓN.}

Amparado en las dos sociedades citadas, el socialismo malagueño fue recuperando fuerza desde los últimos años del siglo XIX, a la par que encontraba eco entre los trabajadores del campo, en particular entre los del corredor Campillos-Teba. En Vélez-Málaga, una vez superadas las dificultades que tuvimos ocasión de comentar, el Círculo Socialista reanudaba sus actividades a partir de julio de 1894, estableciendo su domicilio social en calle Cristo, núm. $17^{29}$. Dos años después, en 1896, los candidatos socialistas por el distrito obtenían 22 votos, lo que sin ser un resultado óptimo podemos considerar como un indicio, aunque sea aproximado, del número de afiliados con que esta fuerza política contaba en el distrito de Vélez. De todas formas, no nos parece muy descabellado pensar que los apoyos sociales con que el social-ugetismo contó a partir del año siguiente podían muy bien acercarse al centenar de afiliados, como parece desprenderse de los datos de que disponemos. En 1897, las cotizaciones enviadas desde la localidad para el sostenimiento de $E l$ Socialista ascendieron a 21,27 pesetas, lo que vendría a corresponderse con algo más de 100 suscripciones (López Estudillo, 1994: 795 n. 138). En junio de 1901, el Círculo Socialista de Obreros contaba con 102 afiliados, la mayoría de ello agricultores, según consta en la "Relación nominal de miembros" remitida por el presidente de la sociedad, Antonio Jiménez, al Gobierno $\operatorname{civil}^{30}$; y ese mismo año el socialista José Verdes Montenegro obtenía el resultado más satisfactorio de los conseguidos hasta entonces en el distrito: 133 votos $^{31}$.

En la capital, el núcleo socialista estaba representado por La Unión Social, cuya primera Junta directiva, elegida en el acto de constitución de la sociedad, estuvo formada por Manuel Gil como Presidente; Francisco Botin, Vicepresidente; Eduardo López, Tesorero; Sixto Díaz, Contador; Andrés Samos, Secretario $1^{\circ}$; Miguel Barrera, Secretario $2^{\circ}$; y José Antúnez, Guillermo López y Manuel Garcia, Vocales. Junto a ellos podemos destacar a Antonio Valenzuela, José Salinas Rueda, José Albuera Carvajal, Enrique Jara Moreno, Manuel Quintana Aigó, Manuel Garcia 
Castro, José Porras Sánchez .......y así hasta aproximadamente medio centenar de afiliados con que contó en los primeros años del nuevo siglo. El análisis socio-profesional que de sus miembros hace Garcia Montoro (1985: 370-371) muestra un predominio de los oficios artesanoindustriales, destacando entre estos los carpinteros y toneleros seguidos de tipógrafos, zapateros y albañiles. Aunque no conviene olvidar la importancia cuantitativa que tenian los agricultores y jornaleros que en 1901 representaban el 40 '8 por ciento del total de afiliados, y que estará en consonancia con la mayor presencia de los mismos a nivel provincial.

De esta forma, a comienzos de 1900 la provincia de Málaga contaba con tres agrupaciones socialistas, al sumarse a los dos núcleos citados la agrupación de El Palo, constituida en enero de ese mismo año. Su existencia, sin embargo, fue relativamente breve, pues puede darse por desaparecida antes de la celebración del VI Congreso del P.S.O.E. en agosto de 1902. Como corta fue también la existencia de la agrupación de Benamocarra, que, fundada en enero de 1901, quedó desorganizada tras varios meses de actividad (Castillo, 1995: 24-27).

Tímidos fueron igualmente los avances experimentados por la Unión General de Trabajadores en la provincia, quedando ya muy lejos aquellos años en que el sindicalismo ugetista había liderado de forma significativa el societarismo obrero. El primer paso en este proceso lo dieron nuevamente los trabajadores de la comarca de Vélez-Málaga. Allí, en noviembre de 1900 la Sociedad de Alpargateros ingresaba en la Unión ${ }^{32}$, que agrupaba en junio de 1902 a todos los miembros del oficio menos a tres ${ }^{33}$; lo que le permitiría durante estos años sostener varias huelgas en reivindicación de una mejora de los salarios ${ }^{34}$. Paralelamente se habían incorporado a la Unión los Tipógrafos de la capital ${ }^{35}$. En octubre de 1901 era la Sociedad Adelante, de El Palo, la que solicitaba el ingreso, y que le sería denegado en varias ocasiones por considerar la Comisión ejecutiva que se trataba de una Sociedad "instructiva y recreativa" ${ }^{36}$. Una decisión que no podemos menos que estimar como paradójica si tenemos en cuenta los objetivos formales que perseguía la antes aludida La Unión Social. La última incorporación conocida para estos años data de diciembre de 1901, cuando se aprobaba el ingreso de la Sociedad de "Artes y Oficios" de El Palo ${ }^{37}$ y que se daba de baja en septiembre de 1903 al no poder pagar la cuota de huelga $^{38}$.

Mención aparte merece el eco que comenzaba a tener el socialugetismo en el campo. Es sabido que el socialismo fue en sus inicios un movimiento predominantemente urbano (Castillo, 1995) que prestó escasa atención a las organizaciones campesinas, lo que no deja de llamar la atención si tenemos en cuenta que entre 1877 y 1900 aproximadamente un 65 por ciento de la población activa española eran agricultores, frente a un 15 por ciento de trabajadores industriales, incluido el artesanado ${ }^{39}$. Por ello, asumiendo los planteamientos "agraristas" de los socialistas alemanes y 
franceses, a partir de 1896 algunos núcleos del socialismo se hicieron eco del tema, publicándose una serie de editoriales y articulos en El Socialista y La Lucha de Clases (Biglino, 1983: 259-260).

Con todo, ello no fue impedimento para que desde años antes el PSOE desplegase una tenue actividad entre el campesinado, particularmente entre el gaditano (Castillo, 1976b), y' para que a partir de 1890 algunas sociedades de agricultores formasen parte del tejido organizativo del sindicato ugetista. Fue este el caso, ciertamente precursor, del socialismo malagueño, al formar parte de la Unión en 1891 cuatro sociedades agrarias: las de Agricultores de Cala de Benalgabón y Jarazmin, y'las de 1 os Hortelanos de Málaga y El Palo ${ }^{40}$.

Pero fue a principios del nuevo siglo, con el progresivo robustecimiento del socialismo español; cuando las preocupaciones por la cuestión agraria se acentuaron, como evidencia la sección que con el título de "Ecos del proletariado agrícola" publicó El Socialista desde el 21 de febrero de 1902, y que perduraría durante mucho tiempo bajo la denominación de "Ecos Agrícolas" (Biglino, 1983: 262 y n.). El punto de inflexión en esta actitud hay que buscarla en la huelga protagonizada por los agricultores de Teba en 1902, que a juicio de P. Biglino (1983: 262) fue el primer conflicto agrario en el que los socialistas desempeñaron un papel importante, y tras la cual, sin embargo, Calero (1979: 53) vio una "mal conocida Federación Andaluza".

Agrupados hasta entonces en la Sociedad de Agricultores y Canteros, que contaba con un millar de socios, a principios de 1902 los agricultores de Teba fueron a la huelga en señal de protesta por el despido de varios jornaleros que habían exigido a un propietario el despido de un capataz acusado de maltratar a un obrero. Pablo Iglesias intervino en el conflicto y. se desplegó una importante campaña de solidaridad en todo el país. Después de 6 meses de resistencia, la huelga concluyó con una negociación: los agricultores y canteros separarían sus sociedades y "todos volverían al trabajo sin represalias y con un ligero aumento de salario para la siega" (Calero, 1979: 52).

A partir de entonces la presencia del campesinado en las filas socialistas fue in-crescendo. En 1904, dos tercios de las 53 sociedades que ingresaron en el Partido estaban compuesta por trabajadores agricolas, en tanto que la UGT contaba entre sus afiliados, en marzo de 1905, con 6.046 campesinos, que representaban más del 10 por ciento del total de sus efectivos (Biglino, 1983: 262). Entre ellos los Agricultores del Centro Obrero de Campillos y los de Vélez-Málaga, que ingresaron en la Unión en junio de $1902^{41}$, y los de Teba, que lo hicieron en octubre de $1903^{42}$. 


\section{Conclusiones.}

Conscientes, como somos, del carácter de aproximación que tienen las páginas precedentes, no parecerá superfluo que hagamos hincapié en la provisionalidad de nuestras conclusiones; lo que no obsta para que consideremos conveniente señalar dos aspectos que a nuestro juicio son relevantes. En primer lugar, la escasa implantación del socialismo en la provincia durante el periodo estudiado, no ya solo por lo que hace al conjunto de la clase sino incluso comparativamente con otras corrientes obreras, tal como se desprende de la Estadistica de la Asociación obrera de $1904^{43}$; algo, por lo demás, nada específico a Málaga, como se deduce de algunos de los estudios dedicados al tema (Gabriel, 1990). Aunque no es menos cierto que una correcta valoración del movimiento socialista debería tener en cuenta aquellas sociedades obreras que aunque no integradas orgánicamente en el social ugetismo se movían en su órbita, como han apuntado Piqueras (1991), para el caso valenciano, y Morales (1994: 440444) para el socialismo malagueño en una etapa posterior. Para el periodo que nos ocupa, un buen ejemplo de lo dicho puede ser el caso de los ferroviarios de la provincia. Aunque inmersos en un proceso de organización "autónomo y profesional" desde finales de los años ochenta (Morales, 1995: 495-527), cuando crearon el 30 de julio de 1889 La Unión Ferroviaria $^{44}$, que estaria presidida a principios del nuevo siglo por José Ortega Campos, a la sazón Presidente de la Agrupación Socialista de la capital $^{45}$; ello no les impidió desempeñar un papel central en la articulación del asociacionismo ferroviario de inspiración socialista en España (Castillo 1983: 207-255).

En segundo lugar y directamente relacionado con lo anterior, la acentuada debilidad orgánica del socialismo malagueño, que abocó en no pocas ocasiones a distintas sociedades y agrupaciones a un proceso de "guadianización" en el que a la fundación seguía, casi sin solución de continuidad, la disolución, después la refundación y así sucesivamente. Un proceso que para Pere Gabriel (1990: 47) se debería a la incapacidad del ugetismo para integrar aquellos colectivos obreros que, incluso cercanos, persistían anclados en el sindicalismo de oficio, probablemente por la supeditación de la UGT al Partido Socialista.

\section{BIBLIOGRAFIA.}

AISA, J. y ARBELOA, V.M. (1975), Historia de la Unión General de Trabajadores (UGT), Madrid, Editorial Zero.

BIGLINO, P. (1983), "Cuestión agraria y marxismo: la elaboración del programa agrario del PSOE", en Estudios de Historia Social, núms. 26-27, pp. 257-331.

CALERO AMOR, A.M. (1979), Movimientos sociales en Andalucia (1820-1936), Madrid, Siglo XXI. 
CASTILLO, S. (1976a), "La influencia de la prensa obrera francesa en El Socialista (1886-1890)", en Revista de Trabajo, núm. 56, pp. 85-136.

CASTILLO S. (1976b), "La actividad del P.S.O.E. en el campo: los casos de Alcalá de los Gazules y Grazalema, 1887-1889", en J.L. GARCIA DELGADO (ed.), La cuestión agraria en la España Contemporánea. VI Coloquio de Pau. Madrid, Edicusa, pp. 259-285.

CASTILLO, S. (1982), "Fuentes para la historia del movimiento obrero: El Socialista (1886-1900)", en AA.V.V.., Metodologia de la historia de la prensa española. Madrid, Siglo XXI, pp. 177-184.

CASTILLO, S. (1983), "Los orígenes de la organización obrera en España: de la Federación de Tipógrafos a la Unión General de Trabajadores", en Estudios de Historia Social, núms. 26-27, pp. 19-255.

CASTILlO, S. (1989), Historia del Socialismo español (1870-1909), Barcelona, Conjunto Editorial.

CASTILLO, S. (1995), "Construir un partido. La odisea socialista, 18791902", en El trabajo a través de la historia. II Congreso de Historia Social de España. Córdoba, 28 y 29 de abril de 1995.

CRESPILLO CARREGALO, F. (1990), Elecciones y partidos políticos en Málaga (1890-1901), Málaga, Diputación Provincial.

FORCADELL ALVAREZ, C. (1994), "Conflicto social y movilización obrera: de la huelga general a la dictadura de Primo de Rivera", en REDERO, M. (Coord.), Sindicalismo y Movimientos Sociales (Siglos XIX$X X)$, Madrid, UGT-Centro de Estudios Históricos, pp. 99 -109

GABRIEL, P. (1990), "Sindicalismo y sindicatos socialistas en Cataluña. La UGT, 1888-1938", en Historia Social, núm. 8, pp. 47-71.

GARCIA MONTORO, C. (1985), "Para una historia del asociacionismo obrero en Málaga: La Unión Social", en Actas III Coloquio Historia Andalucia. Historia Contemporánea, T. I, Córdoba, Publicaciones del M.P.C.Ah. Córdoba, pp. 367-376.

GILLESPIE, R. (1991), Historia del Partido Socialista Obrero Español. Madrid, Alianza Editorial.

GUEREÑA, J.L. (1979), "Un socialiste espagnol en France: José Mesa et L'Egalité de Jules Guesde", en Travaux de L'Institut d'Etudes His aniques et Portugaises de l'Université de Tours. Tours, Publications de l'Université de Tours, 1979, pp. 103-122. 
LOPEZ ESTUDILLO, A. (1994), Conflictividad social agraria y crisis finisecular. Republicanismo y anarquismo en Andalucía, 1868-1900. Tesis de doctorado leída en la Universidad de Bellaterra, Barcelona.

MACARRO, J.M. (1988), "El socialismo en Andalucía (1900-1936)", en S. JULIA (coord.), El socialismo en las nacionalidades y regiones. Madrid, Editorial Pablo Iglesias, pp. 105-118.

MARTINEZ CUADRADO, M. (1973), La burguesía conservadora (18741931). Historia de España Alfaguara VI. Madrid, Alianza Editorial (cit. por la ed. de 1978).

MORALES MUÑOZ, M. (1988), Clases populares y movimiento obrero en Málaga. Del clamor revolucionario a la Primera Internacional (18681874). Málaga, SPICUM.

MORALES MUÑOZ, M. (1989), Málaga la memoria perdida: los primeros militantes obreros. Málaga, Diputación Provincial.

MORALES MUÑOZ, M. (1994), "El mutualismo popular y obrero en la comarca de Antequera,1853-1936", en Revista de Estudios Antequeranos, 2, pp. 421-488.

MORALES MUÑOZ, M. (1995), "El asociacionismo ferroviario en el eje Alora-Bobadilla-Antequera (1904-1936)", en Revista Estudios Antequeranos, 2, pp. 495-527.

MORALES MUÑOZ, M. (1996), "España, 1898: ensayo de historia social", en Baetica, núm. 18 (en prensa).

MORATO, J.J. (1918), El partido socialista obrero. Génesis. Doctrina. Hombres. Organización. Desarrollo. Acción. Estado actual. Madrid, Biblioteca Nueva (cit. por la ed. de 1976).

MORATO, J.J. (1925), La cuna de un gigante. Historia de la Asociación General del Arte de Imprimir. Madrid, José Molina (cit. por la reedición del Ministerio de Trabajo y Seguridad Social).

NADAL SANCHEZ, A. (1986), Patronos. obreros (Historia del Movimiento Obrero en Málaga. 1861-1906), Málaga.

PAREJO BARRANCO, A. (1990), Málaga y los Larios. Capitalismo Industrial y Atraso Económico (1875-1914), Málaga, Arguval.

PEREZ LEDESMA, M. (1979). "La Primera etapa de la Unión General de Trabajadores (1888-1897). Planteamiento sindical $y$ formas de 
organización", en BALCELLS, A. (ed. 1979), Teoria y práctica del movimiento obrero en España (1900-1936), Valencia, Fernando Torres editor, pp. 115-170.

PIQUERAS, J.A. (1991), "Sindicatos y ámbito sindical. Interpretación del ugetismo valenciano", en Historia Social, núm. 9, pp. 17-50.

RALLE, M. (1989), "La sociabilidad obrera en la sociedad de la Restauración (1875-1910)", en La sociabilidad en la España contemporánea. Número especial de Estudios de Historia Social, nums. 50-51, pp. 161-199.

RUBIO DIAZ, A. (1996), Viviendas unifamiliares contra corralones. El barrio obrero de Huelin (Málaga 1868-1900), Málaga, Editorial Miramar.

SERRANO, C. (1979), "El PSOE y la guerra de Cuba (1895-1898)", en Estudios de Historia Social, núms. 8-9, pp. 287-310.

SERRANO, C. (1981), "Guerra y crisis social: los motines de mayo del 98", en Estudios sobre Historia de España (Homenaje a Tuñón de Lara), vol. I, Madrid-UTMP, pp. 439-449.

SOTO CARMONA, A. (1989), El trabajo industrial en la España contemporánea (1874-1936), Barcelona, Anthropos.

TUÑON DE LARA, M. (1977), El movimiento obrero en la historia de España 1. 1832-1899, Barcelona/Madrid, Laia/Taurus.

\section{NOTAS:}

1 Censo de la Población de España según el empadronamiento hecho en 31 de diciembre de 1900. Ministerio de Instrucción y Bellas Artes. Dirección General del Instituto Geográfico y Estadístico. Tomo I. Imprenta de la Dirección General del Instituto Geográfico y Estadístico, 1902.

2 "Málaga. Report by Consul Marston. Male Labor.", en: Labor in Europa. Reports from the Consuls of de United States in the several countries of Europe on the rates of wages, cost of liveng to the laboring classes, past and present wages \& in their several districts, in response to a circular from the departament of states requesting information on theses subjects together with a letter from the Secretary of State transmitting the same to the speaker of the House of Representatives. Washington, Gobernment Printing Office, 1885. 
3 Lúcido y sentido testimonio de estas dificultades es el relato que de las mismas hace José Lorite Castor en el "Prólogo" al folleto de Salinas, Obligado por la burguesía. Refutación de sofismas burgueses. Málaga, Tip. Zambrana Hermanos, 1903.

$4 \quad$ L Égalité. Journal Républicaine Socialiste, 18 y 27 de agosto de 1880.

5 Gobierno Civil de la Provincia de Málaga. "Relación de las Sociedades que existen en la provincia de mi mando en el mes de Diciembre de 1886". Málaga, 3 de Marzo de 1887, en Lista de las Sociedades y Ateneos de Obreros o Asociaciones protectoras de estos que existían en España en $1^{\circ}$ de Enero de 1887. Archivo Histórico Nacional(A.H.N.). Madrid, leg. 575.

$6 \quad$ L 'Egalité. Organe du Parti Ouvrier, (tercera serie), 9 de julio de 1882.

7 Gobierno Civil de la Provincia de Málaga. Estado de las Sociedades literarias y Círculos de recreo y de Obreros o protectores de estos que existen en la provincia. Málaga 17 de Marzo de 1890. A.H.N., leg. 575 .

$8 \quad$ Ibídem.

$9 \quad$ Actas de la Unión General de Trabajadores de España. vol. 1(18881892). Sesión del 23 de septiembre de 1890. Barcelona. Ediciones Grijalbo.(a partir de estos momentos Actas UGT/1: 23 de septiembre de 1890).

10 Ibídem., 7 de octubre de 1890.

11 La Unión Mercantil (24 de agosto de 1889).

12 Ibídem( 4 y 26 de enero de 1891).

13 Ibídem(5 de enero de 1891).

14 El Socialista(3 al 17 de febrero de 1891).

15 Ibídem(24 de marzo de 1893).

16 Boletín Oficial de la Provincia de Málaga(a partir de estos momentos BOPMa), núm 558, de 16 de abril de 1896.

17 BOPMa, núm. 232, de 29 de marzo de 1898.

18 Ibídem, núm. 119, de 22 de mayo de 1901. 
19 Actas UGT/1: 9 de septiembre de 1890.

20 Tbídem., 30 de mayo de 1890.

21 Ibídem., 9 de junio de 1891.

22 El Socialista(24 de julio y 7 de agosto de 1891.

23 Actas UGT/1, 8 de marzo de 1892.

24 Actas UGT/1, 23 de septiembre de 1890.

25 Ibídem., 7 de octubre de 1890.

26 Ibídem., 10 de mayo, 26 de mayo y 2 de agosto de 1892.

27 Agrupación Socialista. Círculo Socialista de obreros. Velez-Málaga, 1893. Negociado de Asociaciones. AGCMa.

28 La Unión Social. Sociedad Instructiva y Recreativa. Málaga, 1896. Negociado de Asociaciones. AGCMa.

29 Agrupación Socialista. Círculo Socialista de obreros. VelezMálaga(Escrito del 6 de julio de 1894). Negociado de Asociaciones. AGCMa.

30 "Relación nominal de los miembros del Círculo Socialista de Obreros. Vélez-Málaga, 16 de junio de 1901. AGCMa.

31 BOPMa., núm. 119, de 22 de mayo de 1901.

32 Actas UGT/2: 1 de enero de 1900.

33 Ibídem., 12 de junio de 1902.

34 Ibídem., 19 de septiembre de 1901 y 12 de junio de 1902.

35 Ibídem., 26 de septiembre de 1901.

36 Ibídem., 30 de octubre de 1901.

37 Ibídem., 12 de diciembre de 1901.

38 Ibídem., 10 de septiembre de 1903.

39 Censo de la Población de España según el empadronamiento hecho en 31 de diciembre de 1877. Dirección General del Instituto Geográfico y 
Estadístico. Tomo I, Madrid, Imprenta de la Dirección General del Instituto Geográfico y Estadístico, 1883, y Censo de la Población de España según el empadronamiento hecho en 31 de diciembre de 1900. Tomo I, Madrid, 1902.

40 El Socialista(13 de noviembre de 1891).

41 Actas UGT/2: 12 y 26 de junio de 1902.

42 Ibídem, 22 de octubre de 1903.

43 I.R.S. Estadística de la Asociación obrera en $1^{\circ}$ de noviembre de 1904., formada por la Sección tercera Técnico-Administrativa. Imprenta de la Sucesora de M. Minuesa de los Ríos, Madrid, 1907.

44 Gobierno Civil de Málaga. Estado de las Sociedades literarias y Círculos de recreo y de Obreros o protectores de estos que existen en la provincia. Málaga, 17 de marzo de 1890. A.H.N., leg. 575.

45 Gobierno Civil de la Provincia de Málaga. Relación de las Sociedades Obreras establecidas en esta Capital y en su término Municipal que se hallan constituidas legalmente $y$ funcionan en la actualidad comprendidas en el artículo $4^{\circ}$ del real decreto de 29 de diciembre último. Málaga, 9 de enero de 1904. Archivo Díaz de Escobar (A.D.E.); y Anuario Zambrana. Guía del Forastero en Málaga e indicador General de la Provincia. Año IV, 1903, Tip. Zambrana Hermanos. 